\title{
Research on the Realization of Makerspace in Higher Education
}

\author{
Yan Li ${ }^{1}$, Wang Liping ${ }^{1}$, Liu Yanling ${ }^{2}$ \\ 1. Information and Computer Engineering of PingXiang University, Ping Xiang 337000, China; \\ 2. Primary Education of PingXiang University, Ping Xiang 337000, China
}

Keywords: Makerspace; Higher Education; Innovation And Entrepreneurship

\begin{abstract}
Internet plus profoundly changes our college students' innovative thinking and methods, also provides a broad space for the show. Makerspace has become an important platform for training innovative and entrepreneurial talents. This paper focuses on breaking the current mode of higher education, how to integrate makerspace into the higher education, which will effectively promote the development of innovative and entrepreneurial education.
\end{abstract}

\section{Introduction}

Makers are actors who like to change their ideas into reality through analysis and creativity. Many years ago, makers make innovative design through their own creative, which shows off the record of this group of amazing creativity and innovative efficiency. With the strong and rapid strength, developed countries especially the United States have shown great advantage in the application of innovative technology[1]. The development of maker is a national strategy project in the United States, and American colleges and universities equip with advanced digital manufacturing tools for hackerspaces, and in daily teaching maker education focus on the cultivation of individual "creator". Now, this wave of makers has swept China and "mass entrepreneurship and crowning innovation" has risen to the national strategy. As the core institutions of talent push, Chinese universities, hackerspaces of the people oriented, public oriented, highly praised innovation, and supporting entrepreneurial has become the direction and important initiatives of university teachers and students in innovation and entrepreneurship[2]. This will provide reference and support for the reform and innovation of innovative and entrepreneurial education in domestic universities, and further provide a steady stream of power and reserve forces for the new era. Chinese can achieve or complete competitive transcendence in Internet plus and 4.0 industrial era.

\section{The idea of introducing makerspace into higher education}

How to introduce the concept of maker into the field of education, it is necessary to change the way of teaching in Colleges and universities. It is from the "teaching->accept" one-way chain of education into the knowledge plane or even more three-dimensional plane multidisciplinary fusion methods[3]. From two aspects to change the way of teaching: subjectively, various teaching methods, such as participatory, cooperative, heuristic, inquiry, case and project, are adopted to let students make full use of knowledge, so that students take the initiative to learn new knowledge, expand their horizons and stimulate their creativity and potential; objectively, the hardware resources of colleges and universities are also changing towards innovation. To construct the hackerspaces, colleges and universities need to provide innovative guidance area, innovative training area, innovative project display area and so on. Although the central task of colleges and universities is still education, but when the students will master the knowledge into their creativity and creation, the school education platform and the creation of the incubator platform two will be combined. To sum up, the construction of makerspace needs to focus on education, and cultivate 
talents with creative, innovative and entrepreneurial abilities as the key development direction[4].

\section{The creation of makerspace}

In the practice of hackerspaces, according to the characteristics and strengths, colleges and universities can design the hackerspaces region with the actual situation of students, with professional knowledge of students[5]. It can reflect the operability of hackerspaces education model. And during the implementation of hackerspaces, the time line should have been planned. When the important time node is completed, the potential and feasible innovative works are hatched, pushed to the market for real operation, and tested by the market. Then, the creation of makerspace in the process of innovation and entrepreneurship can be used as shown in figure 1 .

\section{Innovative ideas $\rightarrow$ Creative team $\rightarrow$ Creative realization $\rightarrow$ Business model}

Figure 1. Innovation and entrepreneurship promotion model

1. Breaking the barriers of departments

Because of the division and independence of the subject knowledge system, educational system and administrative setup in universities and colleges, the professional students, teachers and leaders often lack communication and cooperation in academic cooperation, education and training, the boundaries between the departments are larger and the barriers are thicker. The resources and service resources needed for the construction and operation of the creative space are not to be undertaken and provided by any department alone. The prosperity and development of makerspace in colleges and universities are not the ones that can be driven and produced by a department.

Therefore, the project operation of makerspace is imperative. Only to the project as the center, the development of education, cultivating students' creating ability, promoting innovation and development, various departments jointly set up a comprehensive platform, full participation, break the boundaries of disciplines and subjects with teachers and experts, hackerspaces can truly realize.

Firstly, in order to promote the formation of interdisciplinary and multi-disciplinary project teams, it is necessary to launch and welcome students of various disciplines and majors to participate in the lecture, communication and practice of hackerspaces. Secondly, in order to make full use of the resources and abilities of each department, collaborate and complement in makerspace education and service activities, according to its own characteristics each department establish a different coaching team for the entire school teachers and students to provide services. Finally, in order to deepen exchanges and cooperation between departments by further project oriented approach, colleges need to sign cooperation and construction agreement. The mechanism and content of the agreement are jointly established by the responsible person.

From the interdisciplinary perspective, multidisciplinary integration, multi domain fusion is an important path to develop makerspace. Different types of colleges and universities in the construction of hackerspaces can be based on their own characteristics to integrate different advantages of resources.

2. Guiding students to create maker community

The formation of a maker is a spontaneous act. Community is composed of students with common interests. They are the main players in the maker community. Young college students become an important force in entrepreneurship, they have the will and motivation to innovate and start a business. As the education innovation and entrepreneurial practice platform, the school should provide a more authentic environment for students' daily creative practice, which will help motivate students to take part in practical learning activities and achieve the goal of integration of practice teaching and innovation development. But because of the spontaneity of maker community, most of them lack systematic organization and entrepreneurship planning. As a service sharing platform, the makerspace in Colleges and universities should promote the establishment of different community and studio, let students participate in the community by their will, and give them guidance at the right time. But the makerspace cannot convince the host to win, and cannot hinder their free development. Due to the non-profit nature of student organizations and the economic disadvantage of the students, it is also important for schools to provide relatively convenient 
conditions even financial aid for the development of community organizations, such as fundraising in schools or establishing fund of the makerspace. Colleges and universities should shoulder the task of communication between teams of makers, should make full use of exchanges and docking with other schools', enterprises' or government's teams of makers, and should provide project sharing and service platform for maker community.

3. Innovation resources sharing

Some students who aim at the entrepreneurial master may be experts in mature, but more are close to the popular creator, and there are plenty of rookies that are only interested in new technologies. Some of their creations will put into innovative technology of the market, but the vast majority of works only entertain themselves or the practice of thinking about a shining image, even just for DIY, copy or trans format some of the existing products. How to provide adequate hardware resources for the maker in different levels is a tricky issue, in recent years the prosperity of shared culture provides us with a good reference to solve the problem.

First of all, the establishment of open integrated laboratories is the basis for sharing resources, it provides the majority of the hardware environment required to complete the low cost manufacturing experiment. It should include not only sophisticated technology equipment, but also traditional basic manufacturing tools. And establish a perfect management system of the integrated laboratory, so that the makers can quickly get the necessary resources as well as the status of resources. The goal of open integrated laboratory should be to meet for every maker that interest in its service, and make the students know what and how can they get from the hardware support in the campus. At the same time each product development process, innovation results can be shared in the entire integrated laboratory network.

In addition, through transformation of the traditional sense of the library by Internet plus thinking, so the mission of university libraries is not merely to access books, we should make full use of the library's digital information service system, to help maker space to become a base where do the makers learn experience and exchange resource and information. The library provides them physical space and information consulting services. This emerging cooperative service model makes that the students can search, obtain or exchange off-campus support from economy and technology by government, enterprise, community and other independent experts or groups.

4. Building innovation base with enterprises

Innovation base in development mode of university maker space mainly aims at the process of transforming innovation into industry. In the process of upgrading innovation ability in universities focus on innovative projects with potential, which can be directly implemented in industrial parks or science parks after successful cultivation.

Universities can rely on outstanding scientific innovation teachers to build a of maker space, rely on professional teaching resources, open laboratory and library to build a maker space, and closely cooperation with the regional industry, community to build a new type maker space. A maker space needs strong technology platform inside\&outside the school, such as science park and incubation park and other innovation base to train projects and complete project research, which can introduce all kinds of commercial resources in the process of creativity, innovation and entrepreneurship, and provide professional guidance, training and service to trans format the good ideas into projects,

The major purpose of maker space establishment in the university is making full use of the scientific resources and personnel resources in the university to promote the realization of innovation results, At the same time, the maker space of university can also fully combine the theory and practice in the formation of entrepreneurial atmosphere within the students, so that students has more experience to fit the actual business in market. In the course of realizing the maker space in university, there may be professional deficiencies, unclear direction and other issues. Innovative base-oriented development models can effectively avoid such problems, help us to achieve the maker space education model successfully and reflects its real value.

\section{Summary}

At present, China's maker space practice is still in the exploration stage, in the Held various 
exhibitions, innovation and entrepreneurship activities and other traditional ways still dominate stage various exhibitions, innovation and entrepreneurship match and other traditional ways are still in domination. There is not yet appeared particularly mature maker space in university in terms construction model. Maker space aims at achieving innovation and entrepreneurship education goals. It is necessary to break the existing disciplines, introduce multidisciplinary resources and multi-disciplinary services, to achieve healthy and sustainable development.

\section{Acknowledgements}

This work was supported by Provincial Educational Science Planning Project, Jiangxi Province (No. 17YB276)

\section{References}

[1] Wang Youmei, Chen Zan'an. From Innovation to Entrepreneurship: Construction Model and Enlightenment on Makespace in American Universities [J]. China Educational Technology, 2016 (355):1-6.

[2] Qin Feng, Sun Wenyuan. Analysis of Innovative Talents Training in Universities Based on Makerspace [J]. Technology and education, 2016(5):99-101.

[3] Zhang Mi, Xia Xinbin, Wu Chunying. Research on the Development Mode and Practice of University Makerspace[J]. The Science Education Article Collects, February 2017(A):127-128.

[4] Zeng Mingxing, Huang Wei. Research on the Integration Path Between Maker Education and

Professional Education from the Perspective of Internet Plus[J]. Modern Distance Education Research, 2017(3):67-75.

[5] Hu Yingying. A Probe into the Subjectivity Absence Problem of the Maker Spaces in Colleges and Universities[J]. Pioneering with Science \& Technology, 2016(2):71-72. 